\title{
Fala Materna Dirigida à Criança em Cenários Comunicativos Específicos: Um Estudo Longitudinal
}

\author{
Luciana Fontes Pessôa ${ }^{1}$ \\ Maria Lucia Seidl de Moura \\ Universidade do Estado do Rio de Janeiro
}

\begin{abstract}
RESUMO - Esse estudo longitudinal analisa as características da fala materna dirigida à criança, identificando a transição de cenários comunicativos específicos. Quatro díades mães-bebê foram filmadas dos 13 aos 24 meses da criança. As instâncias de fala materna foram classificadas em sentenças afirmativa, negativa, imperativa e interrogativa e os cenários comunicativos classificados como atencional, convencional ou simbólico. Percebeu-se que há uma tendência do cenário atencional diminuir e do simbólico aumentar sua percentagem de tempo ao longo do desenvolvimento da criança em todas as díades observadas. Tipos específicos de sentenças maternas predominaram em determinados períodos do desenvolvimento. O estudo traz uma contribuição para a literatura relativa à fala materna no desenvolvimento inicial, com dados do contexto brasileiro.
\end{abstract}

Palavras-chave: cenários comunicativos; fala materna; desenvolvimento.

\section{Maternal Speech Directed to Children in Specific Communication Frames: A Longitudinal Study}

\begin{abstract}
This longitudinal study aimed to analyze characteristics of maternal speech directed to children, identifying transitions of mother-child communication settings. Four children from 13 to 24 months old and their mothers were observed longitudinally. The instances of maternal speech were classified as affirmative, negative, imperative and interrogative sentences and the mother-child communication settings were classified as attentional, conventional or symbolic. The percentage of time in attentional and symbolic settings showed a linear relation with the increase of baby's age in all mother-child dyads. Different types of maternal sentences presented diverse patterns of development across time and in the four dyads. The study offers a contribution to the literature on maternal speech and initial language development with data from a Brazilian context.
\end{abstract}

Key-words: Communicational frames; maternal speech; development.

O contato com membros de sua comunidade linguística desde os primeiros dias de vida da criança é de fundamental importância para que ela desenvolva a linguagem. Para a abordagem interacionista do desenvolvimento um fator de grande importância na evolução da capacidade linguística da criança é a linguagem no meio sociocultural. Vila (1995) enfatiza que a experiência proporcionada pelo uso feito da linguagem nas interações interpessoais e, especialmente, de um adulto ao comunicar-se com uma criança, é a sua principal fonte de informação sobre a linguagem em si, sua cultura e o papel da linguagem nesta cultura. A linguagem do interlocutor adulto constitui o principal input linguístico da criança em desenvolvimento. Analisando-o é possível identificar a comunidade do falante, transmitir os modelos socioculturais e adaptar o uso da linguagem no interior do meio/da comunidade que o indivíduo faz parte.

Estudos sobre input linguístico na aquisição de linguagem vêm sendo desenvolvidos desde a década de 1960. Nos anos de 1970, os estudos focalizavam a importância do input materno no desenvolvimento da linguagem inicial (Brown \& Bellugi, 1964; Dunn, Wooding \& Herman, 1977; Fraser \& Roberts, 1975; Snow, Arlman-Rupp, Hassing \& Jobse, 1976).

1 Endereço para correspondência: Rua São Francisco Xavier, $52410^{\circ}$ andar, sala 10.004 Bloco F Bairro: Maracanã - Rio de Janeiro/RJ e-mail: pessoalf@gmail.com
Gradativamente, os estudos voltados apenas para as características gramatical e lexical do discurso materno começaram a considerar aspectos semânticos e a serem direcionados para a compreensão dos aspectos pragmáticos e da função social da fala do adulto. A análise da pragmática era simples e restrita em termos da variação nas expressões comunicativas, não sendo considerados aspectos mais específicos.

Na década de 1980, questões sobre o input ainda eram investigadas, mas um menor número de publicações foi identificado quando comparado à década anterior. Realizaram-se estudos relativos à pragmática e ao uso da fala materna (Penman, Cross, Milgrom-Friedman \& Meares, 1983), relacionaram-se no processo de aquisição de linguagem os aspectos sintáticos e semânticos das sentenças (Bloom, Lahey, Hood, Lifter \& Fiess, 1980).

As características observadas na estrutura e no tipo de conteúdo dos enunciados maternos dirigidos à criança levaram à consideração de que esses enunciados constituem um tipo de input diferenciado (motherese) que leva em conta a idade da criança, seu estágio de desenvolvimento, as concepções e expectativas maternas sobre o nível de desenvolvimento desta e o impacto que este input tem no desenvolvimento da estrutura e na complexidade da linguagem infantil. Gleitman, Newport e Gleitman (1984) verificaram uma relação significativa e positiva entre a complexidade 
da fala materna, medida através de seus enunciados, e o desenvolvimento da linguagem infantil.

Chapman (2000) estudou o processo de aquisição de linguagem infantil considerando acontecimentos históricos e as variações individuais, constatando que as pesquisas de genética e o input do ambiente podem contribuir para uma perspectiva interacionista. Esse autor ressaltou a importância de se relacionar os aspectos naturais e culturais no funcionamento do sistema linguístico e concluiu que o aprendizado da linguagem deve ser visto como uma integração de múltiplos domínios que são aprendidos no início do desenvolvimento.

Hoff e Naigles (2002) investigaram a produção do vocabulário de 63 díades americanas em interação linguística em dois momentos (aos dois anos de idade da criança e 10 semanas depois) observando-as por 25 minutos. Os resultados apontaram que a produção da fala materna em termos quantitativos, com um léxico rico e com complexidade semântica, pode trazer benefícios significativos para o desenvolvimento lexical de crianças na faixa etária estudada.

Neste mesmo período, pode-se ainda destacar estudos enfocando o papel do input no processo de aquisição de linguagem (e.g. Huttenlocher, Vasilyeva, Cymerman \& Levine, 2002; Lidz, Gleitman \& Gleitman, 2003; Weizman \& Snow, 2001), estudos relacionando a fala materna com o desenvolvimento da linguagem infantil (Butler, McMahon \& Ungerer, 2003; Camaioni \& Longobardi, 2001; Howell, 2001; Niwano $\&$ Sugai 2002; entre outros) e estudos enfatizando a importância da perspectiva interacionista e a reciprocidade da díade mãe-criança no processo de aquisição linguística (Hustedt \& Raver, 2002; Tulviste, 2003).

É importante ressaltar o quanto que essas características da fala materna podem estar relacionadas às suas expectativas, estratégias e aos aspectos individuais e culturais. Além disso, as crianças podem desenvolver diferentes formas de apropriação das informações presentes no discurso, e este processo ocorre a partir de características individuais de cada uma.

A revisão da literatura indicou que os diversos aspectos aqui discutidos têm sido investigados em estudos transversais: características pragmáticas da fala materna foram identificadas em diferentes classes sociais (Snow, Arlman-Rupp, Hassing \& Jobse, 1976) e contextos (Dunn, Wooding \& Herman, 1977) e com crianças de diferentes idades (Fraser \& Roberts , 1975), a função da fala materna foi analisada em classes sociais distintas (Snow et al., 1976), assim como aspectos sintáticos e semânticos das sentenças maternas e sua relação com o desenvolvimento da linguagem (Bloom, Lahey, Hood, Lifter \& Fiess, 1980). Os efeitos da frequência e da estrutura do input materno no desenvolvimento da linguagem infantil e o tipo de input materno produzido em classes socioeconômicas distintas (Naigles \& Hoff-Ginsberg, 1998) e em culturas diferentes (Snedeker, Li \& Yuan, 2003) também foram estudados. O papel primordial da interação linguística no processo de aquisição da linguagem e a importância dos jogos e das trocas sociais no processo de aquisição de linguagem (Ratner \& Bruner, 1978) foram identificados, assim como a importância do papel da atenção conjunta no desenvolvimento da linguagem inicial (Tomasello \& Farrar, 1986).
Entre 13 e 24 meses de idade, as crianças progridem dos sinais convencionais para os simbólicos em diversas situações (Tomasello \& Todd, 1983). Poucos são os estudos longitudinais que enfocam essa transição, considerando a díade mãe-criança em observações frequentes, ao longo de um período significativo do desenvolvimento (Adamson \& Bakeman, 1984; Camaioni \& Laicardi, 1985; Camaioni, Aureli, Bellagamba \& Fogel, 2003; Ratner \& Bruner, 1978). No Brasil, nenhum estudo com essas características foi identificado.

Estudos longitudinais como o de Bornstein, Tal e Rahn (1992), foram desenvolvidos. Esses autores analisaram e compararam a linguagem utilizada pelas mães com bebês de cinco e treze meses de idade em quatro culturas diferentes (Argentina, França, Japão e Estados Unidos). Os dois principais aspectos da linguagem foram os relacionados aos dados informativos, que envolviam as perguntas, frases diretas, etc., e os aspectos afetivos, que correspondiam ao uso de sons onomatopéicos, não proposicionais, rimas, sons de animais, etc. Os dados evidenciaram, praticamente para todas as culturas, um maior uso de fala relacionada aos aspectos afetivos com os bebês de cinco meses, ao passo que com os de treze meses as mães utilizaram uma linguagem mais informativa. Isto indica sua sensibilidade às características do desenvolvimento de seu interlocutor.

Camaioni e Longobardi (2001) examinaram características da fala de quinze mães italianas de classe média alta, num estudo longitudinal quando as crianças tinham quatro e oito meses respectivamente em três contextos específicos: brincadeira com brinquedos familiares, brincadeira com brinquedos novos e alimentação. Constatou-se que estas mães produzem mais verbos do que substantivos em todos os contextos analisados. Segundo os autores, este resultado obtido pode ter uma relação direta com a morfologia da língua italiana, o posicionamento e a estrutura das sentenças desta língua. Pode-se salientar, com os resultados obtidos, a importância do conhecimento das estruturas sintáticas da língua estudada, pois esta, de certa forma, influenciará no tipo de sentença emitida pelas mães com seus filhos (FDC) e no processo de aquisição de linguagem inicial destas crianças.

Camaioni, Aureli, Bellagamba e Fogel (2003) descreveram as trajetórias individuais do desenvolvimento de quatro díades mãe-bebê. Para isso, analisaram as transições de cenários comunicativos, observando longitudinalmente essas díades (dois meninos e duas meninas) do décimo ao vigésimo quarto mês de vida da criança. Filmagens individuais de cada díade foram realizadas em um laboratório de brinquedos específicos, quinzenalmente, num período de 10 minutos. Semelhanças e diferenças foram observadas, entre as quais se pode destacar que os cenários comunicativos convencionais e os gestos representacionais serviam de "ponte" entre o cenário comunicativo atencional e o cenário comunicativo simbólico. As observações foram aglutinadas em três blocos, com idades específicas das crianças. Com isso, observou-se que da quadragésima quarta semana à sexagésima sexta semana houve um predomínio do cenário comunicativo atencional em todas as díades, da sexagésima sétima à octagésima quinta semana, o cenário comunicativo atencional também prevaleceu nas díades um, dois e quatro , mas o cenário comunicativo convencional aumentou subs- 
tancialmente, em termos de tempo de ocorrência. Apenas na díade três, identificou-se um predomínio do cenário convencional. Da octagésima sexta semana à centésima quarta, o cenário comunicativo simbólico predominou.

Considerando que aspectos culturais influenciam no processo de aquisição e desenvolvimento da linguagem, uma iniciativa preliminar foi também feita por Pessôa (2001), que identificou os aspectos pragmáticos desta fala, segundo a classificação de Jakobson (1975). Os conteúdos afetivos e cognitivos presentes nas sentenças emitidas pelas mães foram observados. Participaram do estudo dois grupos com díades em que os bebês tinham um e cinco meses, respectivamente, através da observação e registro em vídeo. Os resultados obtidos indicaram que a fala dessas mães estava mais voltada para os aspectos afetivos, acompanhando os resultados de pesquisas realizadas em outras culturas (Bornstein, Tal, \& Rahn, 1992). No entanto, na revisão da literatura brasileira referente à fala materna, não foram identificados estudos envolvendo o acompanhamento longitudinal de transformações da fala materna em cenários comunicativos específicos.

Conhecer as características da fala materna e da criança em etapas iniciais do desenvolvimento e identificar os aspectos sintáticos (tipos de sentenças) e semânticos (conteúdo linguístico) pode colaborar para o conhecimento acerca do desenvolvimento da linguagem infantil nos primeiros dois anos da ontogênese das crianças. Observar os cenários comunicativos nos quais as díades estão interagindo é de especial relevância. Nesse sentido, o presente estudo espera detalhar essa dinâmica de mudança em dois níveis: (a) a do desenvolvimento individual da criança; (b) a de comunicação da díade, a partir de repetidas observações, antes, durante e depois das transições no desenvolvimento, num pequeno número de díades.

\section{Método}

\section{Participantes}

Quatro díades mãe-criança foram filmadas e observadas ao longo de 12 meses do desenvolvimento, no período dos 13 aos 24 meses de idade da criança. Optou-se pela escolha dessa faixa etária porque nesse período identifica-se a produção das primeiras palavras (13 meses) e das primeiras sentenças (24 meses).

Díade 1 - mãe primípara, residente da zona sul do Rio de Janeiro, nível socioeconômico médio, nível superior completo, 30 anos, sexo da criança feminino, família intacta.

Díade 2 - mãe primípara, residente da zona norte do Rio de Janeiro, nível socioeconômico médio, nível superior completo, 35 anos, sexo da criança masculino, família intacta.

Díade 3 - segunda gestação materna, residente da zona sul do Rio de Janeiro, nível socioeconômico médio, cursando a Pós-Graduação, 36 anos, sexo da criança masculino, família intacta.

Díade 4 - mãe primípara, residente da zona sul do Rio de Janeiro, nível socioeconômico médio, nível superior completo, 29 anos, sexo da criança feminino, família intacta.

\section{Procedimento de coleta de dados}

O projeto foi submetido à Comissão de Ética da Universidade do Estado do Rio de Janeiro e aprovado. A coleta de dados para os dois estudos foi orientada pelos princípios básicos de observação em ambiente natural com registro em vídeo (Seidl-de-Moura \& Ribas, 2007). As famílias foram procuradas após informações iniciais e manifestação de interesse em participar do projeto. Novos esclarecimentos foram feitos e, então, assinados os documentos necessários pelas mães (Termo de Compromisso Livre e Esclarecido - TCLE e Permissão Para o Uso de Vídeos e Imagens).

As díades foram visitadas em suas residências e filmadas quinzenalmente do décimo terceiro ao vigésimo quarto mês de vida das crianças (24 sessões por díade) durante 20 minutos. Cada díade foi observada em um contexto de brincadeira, sendo-lhe apresentado um conjunto de brinquedos padronizados, incluindo boneca, cobertor, bule de chá com tampa, duas xícaras de chá, dois pires, duas colheres, telefone celular de brinquedo, carrinho de plástico com um cordão de barbante, dois livros de estórias com figuras, bolinha de borracha e um jogo de potes de encaixe. A criança também poderia utilizar outros brinquedos, não ficando restrita a utilização dos brinquedos padronizados pelo observador.

\section{Procedimento de redução e análise de dados}

Os dados foram categorizados para análise em relação aos aspectos sintáticos, aspectos semânticos e cenários comunicativos. As categorias de análise e variáveis serão apresentadas a seguir.

Em relação aos aspectos sintáticos, as sentenças foram classificadas em: (a) Afirmativas - quando a mãe afirma uma sentença. Por exemplo: "O neném está dormindo."; "O telefone está tocando."; "É a vovô que quer falar com o neném..."; (b) Negativas - quando a mãe dá um sentindo negativo para a sentença emitida. Por exemplo: "O neném não quer leitinho agora não.”; (c) Imperativas/diretivas comportamentais - quando a mãe faz um pedido para a criança. Por exemplo: "Não volta a chorar."; "Vamos esticar essa perninha."; "Levanta a perninha." ; (c) Interrogativas/ elicitivas de conversação - quando a mãe solicita alguma resposta da criança. Por exemplo: "Vamos lavar a cabecinha do neném?"; "De quem é esse ursinho?".

Os aspectos semânticos foram categorizados em: (a) Fala relacionada à criança - quando as emissões são relacionadas a características ou ações específicas da criança. Por exemplo: "Que lindo que o neném fez."; (b) Fala relacionada à díade - quando as emissões são relacionadas a alguma atividade em comum da díade. Por exemplo: "A mamãe está brincando com o neném.”; (c) Fala relacionada a aspectos do contexto - quando as emissões são relacionadas a descrição de aspectos ou objetos específicos do ambiente no qual se encontra a díade. Por exemplo: "Olha lá o neném dormindo"; "O telefone do neném está tocando"; (d) A classificação dos cenários comunicativos das díades foi a mesma utilizada por Camaioni, Aureli, Bellagamba e Fogel (2003), considerando o nível de atividade compartilhada entre os parceiros (mãe e criança). 
Os cenários foram classificados em: (a) Atencional quando a díade compartilha um foco comum de atenção, havendo ações literais sobre determinado objeto, tais como: bater, sacudir, combinar objetos etc; (b) Convencional quando a díade compartilha significado convencional de ações ou sinais. Exemplos: jogos de dar e pegar; brincadeira de esconder e aparecer, etc; (c) Simbólico - quando a díade compartilha relações com referentes significados, como conversar sobre um objeto comum. Exemplos: brincadeira de apontar e nomear objetos, jogos de alfabeto e números, cantar juntos, contar histórias juntos, fazer de conta etc; (d) Não ocorrência - quando não existe um foco de atenção compartilhado pela díade.

Os cenários comunicativos das díades foram identificados e as falas maternas foram transcritas. Cada instância de cenário comunicativo teve sua duração contabilizada. Para cada sessão calculou-se a porcentagem de tempo em cada cenário específico, inclusive quando não era possível identificar a ocorrência dos mesmos. A unidade de análise da fala materna (emissões maternas) foi delimitada por pausas que fazem em sua fala, sem considerar um tempo mínimo para essas pausas, independentemente da sentença estar ou não completa. Dessa forma, em uma única sentença, podem-se encontrar duas ou mais emissões/enunciados. Contabilizou-se o total de emissões maternas dentro dos cenários comunicativos e o total de emissões maternas quando estes cenários não eram estabelecidos. Apenas foram consideradas as falas das mães dirigidas às crianças. A partir dessas categorizações foi organizada a base de dados para análises no SPSS.

Foram construidas curvas para observar as transformações em diversos processos estudados ao longo dos 12 meses: o tipo de fala materna; a porcentagem de tempo nos cenários; instâncias dos tipos de falas das mães dentro dos cenários, observando-se as falas produzidas quando a díade está em engajamento e quando este engajamento não se estabelece. A trajetória da curva das emissões de sentenças maternas foi analisada através de ajustamento de curva (curve fitting) polinomial aos dados, sendo utilizado o princípio da parcimônia como critério de escolha do polinômio, ou seja, a menor ordem do polinômio significante a $5 \%$ usando o teste $F$ foi selecionada. Foi calculado ainda o total de emissões maternas nos seus aspectos sintáticos e semânticos e a média de ocorrência desses aspectos ao longo dos 12 meses de idade da criança.

A avaliação de fidedignidade da codificação dos dados foi feita calculando-se a concordância entre observadores utilizando $16 \%$ do material analisado. Obteve-se um índice de $98,76 \%$ de concordância na análise das categorias da fala materna e 93,51\% na análise dos cenários comunicativos.

\section{Resultados}

A observação das díades estudadas indicou a presença constante da fala materna dirigida às crianças, com especificidades sintáticas e semânticas. Foi possível identificar aspectos comuns e diferenças quantitativas na comunicação das diferentes díades. Os resultados serão apresentados por díade e relacionados aos objetivos do presente artigo.
Díade 1 - observou-se um crescente aumento das emissões maternas proferidas ao longo do período estudado. Houve uma variação de 67 ocorrências, na primeira sessão para 287 emissões maternas, na última. O número máximo de emissões encontradas nessa díade aconteceu na última sessão analisada. Em média a mãe proferiu 180 emissões por sessão observada.

Díade 2 - nesta díade, ao contrário da variabilidade observada na Díade 1, o número de emissões maternas proferidas ao longo do período estudado manteve-se constante. Em média essa mãe proferiu 276 emissões por sessão observada. Nessa díade não foi observada uma tendência de trajetória significativa referente ao total de sentenças maternas produzidas em relação à idade da criança. Isso pode ser um indicativo de que desde cedo, esta mãe considera seu filho como um sujeito ativo, com capacidades de engajamento e para o estabelecimento de trocas. Em muitos momentos, foi possível observar que essa mãe se apropriava das pistas fornecidas pelo seu filho e a partir delas tentava estabelecer e manter um canal aberto de comunicação entre eles.

Díade 3 - Nesta díade não foi possível identificar uma tendência de trajetória significativa específica das emissões maternas proferidas ao longo do período estudado. Houve uma grande variabilidade de 69 a 431 emissões maternas. Em média a mãe proferiu 276 emissões por sessão observada.

Díade 4 - Nesta díade, ao contrário do que foi constatado nas díades anteriores, observou-se um decréscimo nas emissões maternas proferidas ao longo do período estudado. Houve uma variação de 201 a 637. Em média a mãe proferiu 427 emissões por sessão observada. A diminuição de emissões de sentenças materna parece indicar que essa mãe, com o passar do tempo, estimula sua filha a realizar as atividades de forma mais independente. Pode ser que a diminuição no número de ocorrências da fala materna ao longo do período observado possa estar relacionada com o fato da criança explicitar, de forma mais nítida, através da linguagem verbal, um engajamento nas atividades realizadas, estimulando sua mãe deixá-la, o mais a vontade possível, conduzir as situações.

\section{Análise dos aspectos sintáticos}

Díade 1 - Considerando-se os aspectos sintáticos da fala materna, as sentenças afirmativas constituem em média $55,46 \%$ do corpus total, com uma variabilidade entre $43 \%$ e $63 \%$, de sentenças afirmativas proferidas pela mãe ao longo do período. A mãe profere sentenças interrogativas em média $25,62 \%$ ao longo das sessões, numa faixa de $18 \%$ e $34 \%$. As sentenças imperativas também estão presentes, em média constituem $15,93 \%$ das sentenças da mãe dirigidas à criança (de $9 \%$ a $28 \%$ ). Finalmente, as sentenças negativas aparecem em menor proporção $2,98 \%$, variando entre $0 \%$ e $7 \%$ ao longo das sessões.

Díade 2 - Considerando-se os aspectos sintáticos da fala materna, as sentenças afirmativas constituem em média $57,94 \%$ do corpus, com uma variabilidade entre $29 \%$ e $71 \%$ de sentenças afirmativas proferidas pela mãe. A mãe também emite sentenças interrogativas: em média 19,46\% ao longo das sessões, numa faixa de $8 \%$ e $46 \%$. As sentenças 
imperativas também estão presentes, em média constituem $15,84 \%$ das sentenças da mãe dirigidas à criança (de $4 \%$ a 39\%). Finalmente, as sentenças negativas aparecem em menor proporção $6,76 \%$ variando entre $1 \%$ e $12 \%$ ao longo das sessões. Em termos de percentagem é possível identificar que os índices foram semelhantes ao da Díade 1.

Díade 3 - Considerando-se os aspectos sintáticos da fala materna, as sentenças afirmativas constituem em média $55,71 \%$ do corpus, com uma variabilidade entre $41 \%$ e $67 \%$, de sentenças afirmativas proferidas pela mãe. A mãe também profere sentenças interrogativas: em média $26,48 \%$ ao longo das sessões, numa faixa de $16 \%$ e $38 \%$. As sentenças imperativas também estão presentes, em média constituem $11,89 \%$ das sentenças da mãe dirigidas à criança (de $3 \%$ a $23 \%$ ). Finalmente, as sentenças negativas aparecem em menor proporção 5,92\% variando entre 1\% e 13\% ao longo das sessões. Essas sentenças negativas estavam diretamente vinculadas às atividades que a criança poderia ou não fazer, ou seja, assim como foi dito na Díade 1. Este tipo de sentença pode estar diretamente relacionado com o fato da mãe estar atribuindo uma maior capacidade de entendimento de seu filho para as regras de socialização.

Díade 4 - Considerando-se os aspectos sintáticos da fala materna, as sentenças afirmativas constituem em média $50,97 \%$ do corpus, com uma variabilidade entre $44 \%$ e $58 \%$, de sentenças afirmativas proferidas pela mãe. As sentenças imperativas também estão presentes, em média constituem $26,64 \%$ das sentenças da mãe dirigidas à criança (de 14\% a $35 \%$ ). A mãe também profere sentenças interrogativas: em média $19,69 \%$ ao longo das sessões, numa faixa de $12 \%$ e $27 \%$. Finalmente, as sentenças negativas, assim como nas outras díades observadas, aparecem em menor proporção $2,70 \%$ variando entre $1 \%$ e $4 \%$ ao longo das sessões.

\section{Análise dos aspectos semânticos}

Díade 1 - A mãe se refere principalmente ao contexto mais próximo em que ela e a criança estão inseridas, em média $80,15 \%$ (entre $41 \%$ e 100\%). Ela fala, principalmente, sobre os brinquedos do cenário. A mãe também fala sobre a criança e sobre a díade. No primeiro caso isso ocorreu em média $15,83 \%$ das sentenças, variando entre $0 \%$ e $54 \%$ ao longo das sessões. Ao falar sobre a criança, a mãe centra-se nos adjetivos e nos elogios atribuídos ao seu filho. Menos frequentes são as sentenças que têm como foco a própria díade, em média $2,15 \%$ das emissões maternas diz respeito a características e atividades próprias da díade com uma variabilidade entre $0 \%$ e $10 \%$.

Díade 2 - A mãe se refere principalmente ao contexto mais próximo em que ela e a criança estão inseridas, em média $82,16 \%$ (entre $48 \%$ e $96 \%$ ). Ela fala, assim como na Díade 1, principalmente, sobre os brinquedos do cenário onde a díade se encontra. A mãe também fala sobre a criança e sobre a própria díade. No primeiro caso isso ocorreu em média $15,63 \%$ das sentenças, variando entre $2 \%$ e $52 \%$ ao longo das sessões. Ao falar sobre a criança, a mãe focaliza nos adjetivos e nos elogios atribuídos ao seu filho. Menos frequentes são as sentenças que têm como foco a própria díade, em média 2,19\% das emissões maternas diz respeito a características e atividades próprias da díade com uma variabilidade entre $0 \%$ e $5 \%$.

Díade 3 - A mãe se refere principalmente ao contexto mais próximo em que ela e a criança estão inseridas, em média $88,37 \%$ (entre $71 \%$ e $97 \%$ ). Ela fala, principalmente, sobre os brinquedos do cenário. A mãe também fala sobre a criança e sobre a díade. No primeiro caso, isso ocorreu em média $8,89 \%$ das sentenças, variando entre $1 \%$ e $26 \%$ ao longo das sessões. Ao falar sobre a criança, a mãe focaliza nos adjetivos e nos elogios atribuídos ao seu filho. Menos frequentes são as sentenças que têm como foco a própria díade, em média $2,81 \%$ das emissões maternas diz respeito a características e atividades próprias da díade com uma variabilidade entre $0 \%$ e $10 \%$.

Díade 4 - A mãe se refere principalmente ao contexto mais próximo em que ela e a criança estão inseridas, em média $92,05 \%$ (entre $86 \%$ e $98 \%$ ). Nesta díade obteve-se a menor média de fala materna relacionada à criança, isso ocorreu em média 4,62\% das sentenças, variando entre $1 \%$ e $11 \%$ ao longo das sessões. Ao falar sobre a criança, a mãe focaliza nos adjetivos e nos elogios atribuídos ao seu filho. Menos frequentes são as sentenças que têm como foco a própria díade, em média 3,32\% das emissões maternas diz respeito a características e atividades próprias da díade com uma variabilidade entre $0 \%$ e $7 \%$.

\section{Análise do engajamento da díade em cenários comunicativos específicos}

Díade 1 - Em geral, nas sessões de observação, mãe e filha estavam engajadas em cenários comunicativos, em parte pela própria estrutura da tarefa proposta. Apenas em 18,46\% de tempo em média, não foi observada ocorrência de algum tipo desses cenários.

Constataram-se trajetórias lineares para a percentagem de tempo de todos os cenários comunicativos observados, isto é, atencional $F(1,22)=15,66, \mathrm{p}<0,05)$, convencional $F(1,22)=6,20, \mathrm{p}<0,05)$ e simbólico $F(1,22)=28,13$, $\mathrm{p}<0,05$, em relação à idade da criança, umas crescentes e outras decrescentes. Encontrou-se também uma trajetória linear para a percentagem de tempo de não ocorrência de cenário comunicativo em relação à idade da criança $F(1$, $22)=4,33, p<0,05$. O tempo de engajamento em cenário atencional (exploratório) diminui, a partir da $62^{\mathrm{a}}$ semana da criança, assim como em cenários convencionais (quando há um foco comum através de significados convencionais baseados em ações não literais definidas e compartilhadas culturalmente). A percentagem de tempo deste cenário convencional cai, no entanto, nas $60^{\mathrm{a}}$ e na $68^{\mathrm{a}}$ semanas, quando o cenário atencional predomina e somente a partir da $76^{\mathrm{a}}$ semana que o cenário convencional diminui progressivamente. Por outro lado, aumenta, a partir da $77^{\mathrm{a}}$ semana em diante, o engajamento em cenários simbólicos, com o desenvolvimento da criança, inclusive seu desenvolvimento linguístico, tanto em termos de compreensão quanto de produção de vocabulário.

Díade 2 - Em geral, nas sessões de observação, mãe e filho estavam engajados em cenários comunicativos, em parte pela própria estrutura da tarefa proposta. Apenas em 23,24\% 
de tempo em média, não foi observada ocorrência de algum tipo desses cenários comunicativos.

Constatou-se, assim como na Díade 1, uma trajetória linear negativa significativa para a percentagem de tempo do cenário comunicativo atencional em relação à idade da criança $F(1,22)=26,32, p<0,05$, uma trajetória linear positiva significativa para percentagem de tempo do cenário comunicativo convencional $F(1,22)=5,24, p<0,05$ e para percentagem de tempo do cenário simbólico $F(1,22)=10,26$, $p<0,05$ em relação à idade da criança. Essas trajetórias eram esperadas pelas próprias noções básicas do desenvolvimento. Pelo fato do cenário comunicativo atencional ser um cenário mais exploratório, em que a linguagem da criança ainda não está presente, a tendência esperada é que com o passar do tempo, a partir do momento em que a criança vai adquirindo a linguagem verbal, essas tarefas mais exploratórias sejam enriquecidas pela fala. Percebe-se, que há um decréscimo no tempo desses cenários atencionais, a partir da $62^{\mathrm{a}}$ semana. $\mathrm{Na}$ medida em que a linguagem vai sendo adquirida, pela compreensão e posteriormente pela produção, os cenários comunicativos convencionais se ampliam, justamente na $62^{\mathrm{a}}$ semana, período em que as atividades exploratórias já não são mais constantes. Lembrando que no cenário convencional, a criança compreende o que a mãe fala, mas ainda não produz as palavras, com isso, os cenários convencionais decresceram na $82^{\mathrm{a}}$ semana, com o avançar do cenário comunicativo simbólico, em que as palavras já são emitidas pelas crianças.

Díade 3 - Em geral, nas sessões de observação, mãe e filho estavam engajados em cenários comunicativos, em parte pela própria estrutura da tarefa proposta. Apenas em 39,43\% de tempo em média, não foi observada ocorrência de algum tipo desses cenários. Vale ressaltar, o fato da irmã da criança em observação estar presente no ambiente da filmagem e em algumas vezes, demandar a atenção de sua mãe. Isso, de certa forma, pode ter interferido nessa maior percentagem de tempo de não ocorrência desses cenários comunicativos quando comparada às percentagens de não ocorrência das outras díades do estudo.

Foi possível observar uma trajetória linear significativa, no sentido negativo, para a percentagem de tempo de cenário comunicativo atencional em relação à idade da criança $F$ $(1,22)=12,94, \mathrm{p}<0,05$. A porcentagem de tempo nos cenários de tipos convencional e simbólico não apresentou tipos de trajetórias específicas quando relacionados à idade da criança. A não ocorrência de cenários comunicativos também não apresentou uma tendência de trajetória quando relacionado à idade da criança.

Díade 4 - Em geral, nas sessões de observação, mãe e filha estavam engajadas em cenários comunicativos, em parte pela própria estrutura da tarefa proposta. Apenas em 16,46\% de tempo em média, não foi observada ocorrência de algum tipo desses cenários. Constatou-se, assim como nas outras díades, uma trajetória linear negativa significativa para a percentagem de tempo do cenário comunicativo atencional em relação à idade da criança $F(1,22)=11,01, p<0,05$. Uma trajetória linear positiva significativa também foi encontrada para percentagem de tempo do cenário simbólico em relação à idade da criança $F(1,22)=17,14, p<0,05$. As Figuras 1,2 e 3 mostram as trajetórias dessas curvas ao longo do período observado nas quatro díades:

\section{Discussão}

Os dados obtidos sugerem que as mães ajustam suas emissões linguísticas, de modo a conseguir chamar a atenção do seu filho para si, para suas emissões e principalmente, para o contexto/meio em que estão inseridos. Afinal, a condição necessária para que se estabeleça uma forma de comunicação verbal entre a díade é que a criança esteja com sua atenção

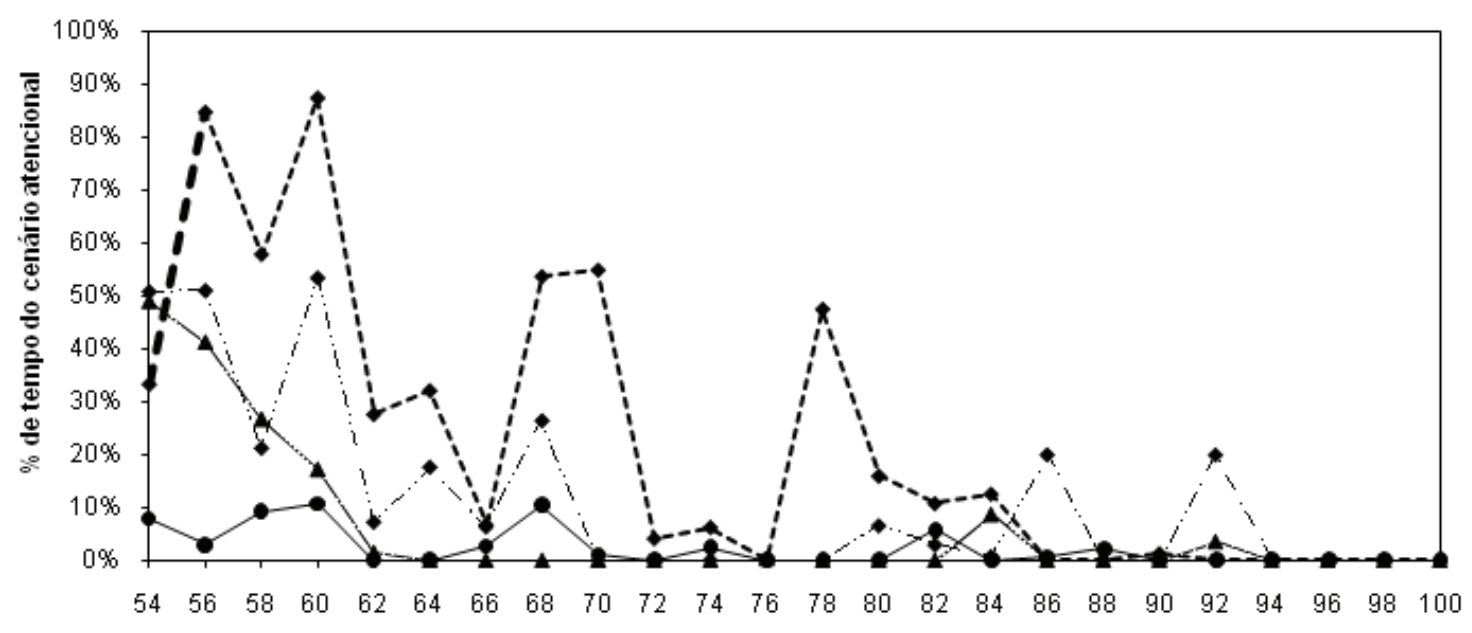

Idade do bebê (em semanas)

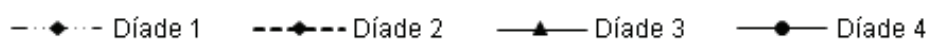

Figura 1. Trajetória do cenário comunicativo atencional ao longo das 48 semanas. 


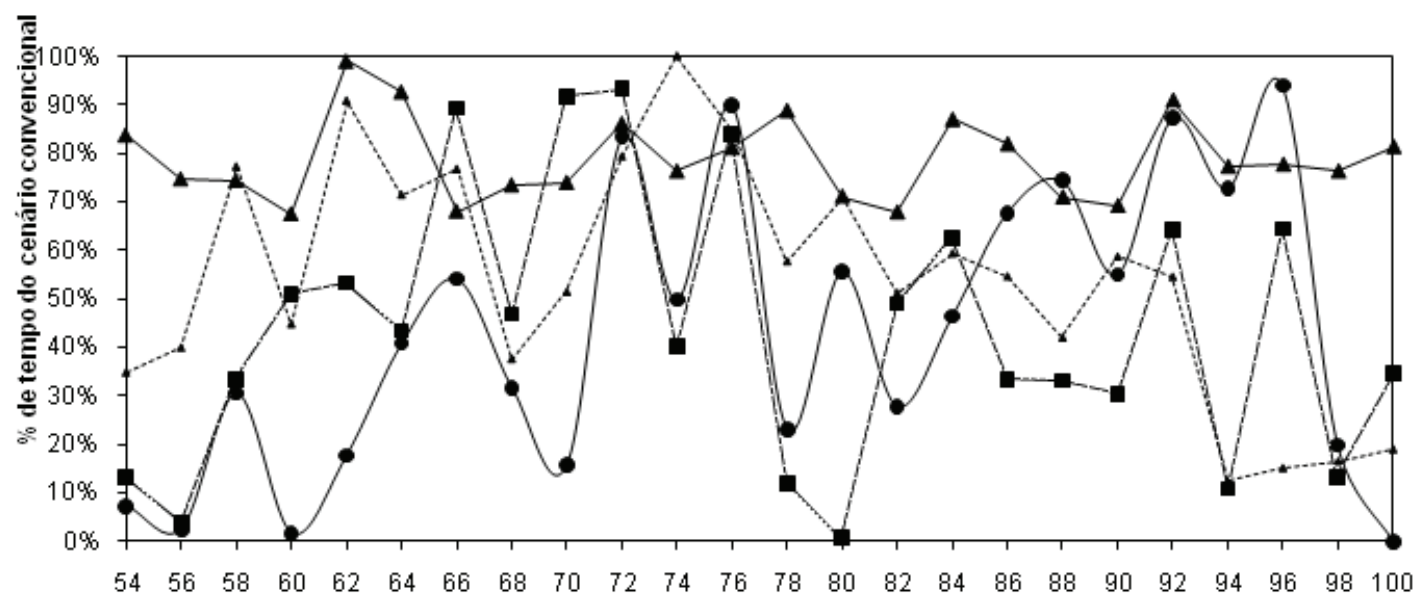

Idade do bebê (em semanas)

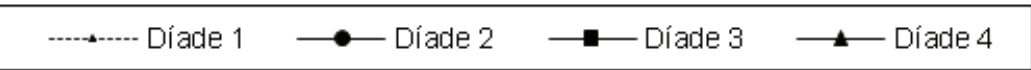

Figura 2. Trajetória do cenário comunicativo convencional ao longo das 48 semanas
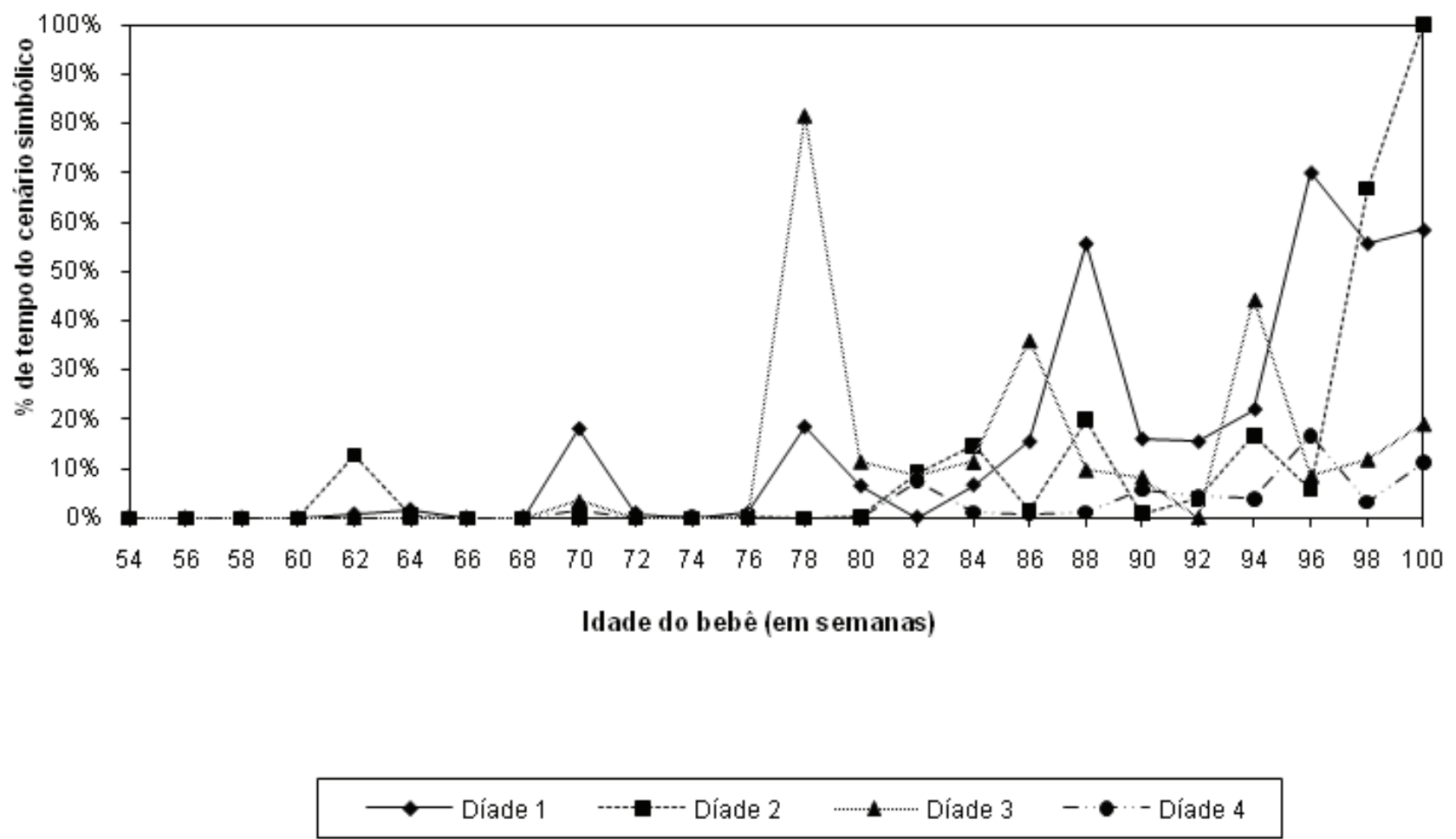

Figura 3. Trajetória do cenário comunicativo simbólico ao longo das 48 semanas

voltada para a mãe. Intuitivamente, a mãe utiliza este recurso linguístico, através de suas sentenças afirmativas, negativas, imperativas e interrogativas, para chamar ou manter a atenção do (a) filho(a) voltada para ela e para as situações que os (as) envolvem.

A partir das observações realizadas, identificou-se que as mães desse estudo, falam sobre a própria criança, sobre as atividades realizadas conjuntamente pela díade e princi- palmente, sobre as coisas e pessoas do contexto que está a sua volta.

Algumas diferenças entre as díades observadas foram encontradas, que podem ser atribuídas a características individuais das mães, mas inegavelmente o desenvolvimento da criança parece ser a variável mais importante a ser hipotetizada para explicar as variações no tipo e no conteúdo das falas maternas. 
$\mathrm{O}$ aumento significativo da fala materna relacionada ao contexto, ao longo do desenvolvimento da criança, parece indicar que as mães atribuem uma maior compreensão acerca dos fatos que estão ocorrendo no meio em que estão inseridos quando esta têm mais idade. A mãe, então, utiliza-se dos recursos linguísticos, através dos diferentes tipos de sentenças (afirmativas, imperativas e negativas) para transmitir, então, as normas, as regras, formas de comportamentos adequados, tentando educar seu (sua) filho (a) para a vida cotidiana.

Além disso, o uso de imperativos, ao longo do desenvolvimento, pode significar uma tentativa das mães de imprimir uma organização à conduta de suas crianças e às suas próprias, além de ser uma forma verbal de interagir com elas. A ocorrência de emissões interrogativas é mais um indicativo do estabelecimento de interação linguística que, juntamente com as pausas, apontam virtualmente para a alternância de interlocutor, que é fundamental em um processo de interação verbal.

Também foi possível constatar na análise dos dados que quase todos os enunciados maternos são diretamente precedidos ou seguidos pelos sinais das crianças. Isso significa que as mães não estão simplesmente comunicando informação para seus filhos, mas estão tentando engajá-los em conversas (Snow, 1986).

Um aspecto importante que pode ser associado ao crescimento da competência linguística é o engajamento/ interação das díades ao longo do desenvolvimento infantil. Assim como demonstrado nos estudos de Tomasello e Todd (1983) as crianças que passavam mais tempo em atividades interativas com suas mães, mantinham altos níveis de foco de engajamento durante sessões não estruturadas de jogos, entre os doze e dezoito meses e tinham vocabulário mais amplo em geral e maior vocabulário nominal específico aos dezoito meses.

A média de engajamento das díades nos cenários comunicativos específicos do estudo foi de $76 \%$ do tempo total de observação. Enquanto o tempo de engajamento das díades nos cenários comunicativos atencionais diminui a partir da $62^{\mathrm{a}}$ semana, como observado nas díades 1,2 e 3, os cenários comunicativos simbólicos aumenta, em termos de percentagem de tempo de ocorrência, na $82^{\mathrm{a}}$ semana, como também aconteceu nas díades 2 e 4 . Percebe-se que há uma tendência do cenário comunicativo atencional diminuir ao longo do desenvolvimento. A diminuição desse cenário ocorre por volta da $62^{\mathrm{a}}$ semana, e a partir de então, se verifica a predominância dos cenários comunicativos convencionais, e também, o aumento da percentagem de tempo dos cenários comunicativos simbólicos em momentos distintos nas quatro díades do estudo. Esse aumento dos cenários simbólicos ocorre a partir do desenvolvimento linguístico verbal da criança e sua consequente, produção de palavras do vocabulário. Os resultados obtidos nesse estudo vão na mesma direção dos encontrados por Camaioni, Aureli, Bellagamba e Fogel (2003).

Acredita-se, assim como Slade (1987), que a figura materna contribua para o crescimento dos cenários simbólicos, já que fornece o apoio concreto para que as estruturas cognitivas possam emergir, respondendo às primeiras palavras da criança, criando os significados compartilhados que propiciam o desenvolvimento da capacidade de representação. Não se pode deixar de mencionar, também, sua disponibilidade emocional fornecendo à criança uma sensação essencial de segurança que é necessária para suas explorações do mundo.

Constatou-se, mais uma vez, a importância de se levar em conta atitudes, comportamentos e formas de agir dos sujeitos. Ao se estudar, principalmente, o comportamento humano, não se pode dissociá-lo de seu contexto, de sua cultura. Cada cultura tem suas especificidades que precisam ser levadas em conta. Com base nessas diversidades e especificidades culturais, intensifica-se a necessidade de pesquisas em diferentes culturas, mesmo na investigação de processos básicos e universais como o desenvolvimento inicial da linguagem.

Entende-se também que o avanço na área de investigação acerca da interação mãe-bebê e do desenvolvimento linguístico infantil depende, em larga medida, da produção de evidências empíricas relativas a aspectos envolvidos nesses processos. Nesse sentido, considera-se a necessidade de que se desenvolvam e aperfeiçoem metodologias de observação da interação mãe-bebê e do desenvolvimento linguístico, com variações que podem incluir classes sociais diferenciadas ou pesquisas de laboratório.

Estudos longitudinais são particularmente importantes, porém escassamente desenvolvidos. O presente trabalho tem algumas limitações, como a de propor uma situação específica de brincadeira, de terem sido realizadas filmagens de sessões quinzenais e de envolver apenas 24 observações de quatro díades e não poder resgatar a fala da criança durante as sessões, limitando-se a utilizar dados de relato das mães para acompanhar o desenvolvimento linguístico das crianças. Contudo, pode ser considerado um primeiro passo no avanço de estudos que buscam a compreensão da ontogênese, ou seja, procuram identificar as particularidades de alguns processos do desenvolvimento humano, como o do desenvolvimento da linguagem inicial. Acredita-se que os resultados descritos contribuam para o conhecimento do desenvolvimento da linguagem infantil nos primeiros dois anos da ontogênese das crianças.

\section{Referências}

Adamson, L. B., Bakeman, R. (1984). Mothers' communicative acts: Changes during infancy. Infant Behavior and Development, 7, 467-478.

Bloom, L., Lahey, M., Hood, L., Lifter, K., \& Fiess, K. (1980). Complex sentences: Acquisition of syntactic connectives and the semantic relations the encode. Journal of Child Language, $7(2), 235-261$.

Bornstein, M. H., Tal, J., \& Rahn, C. (1992). Functional analysis of the contents of maternal speech to infants of 5 and 13 months in four cultures: Argentina, France, Japan, and United States. Development Psychology, 28(4), 593-603.

Brown, R., \& Belluggi, U. (1964). Three processes in child's acquisition of syntax. In E. A. Lennerberg (Ed.), New directions in the study of language (pp.133-161). Cambridge, Mass: The MIT Press.

Butler, S., McMahon, C., \& Ungerer, J. A. (2003). Maternal speech style with prelinguistic twin infants. Infant and Child Development, 12(2), 129-143. 
Camaioni, L., Aureli, T., Bellagamba, F., \& Fogel, A. (2003). A longitudinal examination of the transition of symbolic communication in the second year of life. Infant and Child Development, 12(2), 1-26.

Camaioni, L., \& Laicardi C. (1985). Early social games and the acquisition of language. British Journal of Developmental Psychology, 3, 31-9.

Camaioni, L., \& Longobardi, E. (2001). Noun versus verb emphasis in Italian mother-to-child speech. Journal of Child Language, 28, 773-785.

Chapman, R. S. (2000). Children's language learning: An interactionist perspective. Journal of Child Psychology and Psychiatry, 41, 33-54.

Dunn, J., Wooding, C., \& Herman, J. (1977). Mothers' speech to young children: variation in context. Developmental Medicine and Child Neurology, 19(5), 629-638.

Fraser, C., \& Roberts, N. (1975). Mothers' speech to children of four different ages. Journal of Psycholinguistic Research, 4(1), 9-16.

Gleitman, L. R., Newport, E. L., \& Gleitman, H. (1984). The current status of the motherese hypothesis. Journal of Child Language, 11, 43-79.

Hoff, E., \& Naigles, L. (2002). How children use input to acquire a lexicon. Child Development, 73(2), 418-433.

Howell, C. S. (2001). Mothers' speech with 12-moth-old infant: Influences on the amount and complexity of infants' vocalizations. Dissertation Abstract International Sections: Humanities and Social Sciences, 61(12A), 4751.

Hustedt, J. T., \& Raver, C. C. (2002). Scaffolding in low-income mother-child dyads: Relations with joint attention and dyadic reciprocity. International Journal of Behavioral Development, 26(2), 113-119.

Huttenlocher, J., Vasilyeva, M., Cymerman, E., \& Levine, S. (2002). Language input and child syntax. Cognitive Psychology, 45, 337-374.

Jakobson, R. (1975). Lingüistica e comunicação. São Paulo: Cultrix.

Lidz, J., Gleitman, H., \& Gleitman, L. (2003). Understanding how input matters: Verb learning and the footprint of universal grammar. Cognition, 73, 135-176.

Naigles, L., \& Hoff-Ginsberg, E. (1998). Why are some verbs learned before others verbs? Effects of input frequency and structures on children language. Journal of Child Language, $25,95-120$.

Niwano, K., \& Sugai, K. (2002). Intonation contour of Japanese maternal infant-directed speech and infant vocal response. Japanese Journal of Special Education, 39(6), 59-68.

Penman, R., Cross, T., Milgrom-Friedman, J., \& Meares, R. (1983). Mothers' speech to prelingual infants: A pragmatic analysis. Journal of Child Language, 10(1), 17-34.
Pessôa, L. F. (2001). A análise da fala materna dirigida a bebês em duas etapas do desenvolvimento. Monografia de Graduação. Rio de Janeiro, UERJ.

Ratner, N., \& Bruner, J. (1978). Games, social exchange and the acquisition of language. Journal of Child Language, 5(3), 391-401.

Seidl-de-Moura, M. L., \& Ribas, A. F. P. (2007). A pesquisa observacional e o estudo da interação mãe-bebê. In C. A. Piccinnini \& M. L. S. de Moura (Eds.), Observando as primeiras interações pais-bebê-criança: diferentes abordagens teóricas e metodológicas (pp.103-130). São Paulo: Casa do Psicólogo.

Slade, A. (1987). A longitudinal study of maternal involvement and symbolic play during the toddler period. Child Development, 58, 367-375.

Snedeker, J., Li, P., \& Yuan S. (2003). Cross-cultural differences in the input to early word learning. Proceedings of the Twenty-fifth Annual Conference of Kirkland. Cambridge.

Snow, C. E. (1986). Conversations with children. In P. Fletcher \& M. Garman (Eds.), Language Acquisition (pp. 363-375). Cambridge: CUP Second Edition.

Snow, C. E., Arlman-Rupp, A., Hassing, Y., \& Jobse, J. (1976). Mothers' speech in three social classes. Journal of Psycholinguistic Research, 5(1), 1-20.

Tomasello, M., \& Farrar, M. J. (1986). Joint attention and early language. Child Development, 57, 1454-1463.

Tomasello, M., \& Todd, J. (1983). Joint attention and lexical acquisition style. First Language, 4, 197-212.

Tulviste, T. (2003). Contextual variability in interactions between mothers and 2-year-olds. First Language, 23(3), 311-325.

Vila, I. (1995). Aquisição de linguagem. In C. Coll, J. Palácios \& A. Marchesi (Eds.), Desenvolvimento psicológico e educação. Porto Alegre: Artes Médicas.

Weizman, Z. O., \& Snow, C. E. (2001). Lexical output as related to children's vocabulary acquisition: Effects of sophisticated exposure and support for meaning. Developmental Psychology, $37(2), 265-279$. 